\title{
The effect of FOXA2 rs1209523 on glucose-related phenotypes and risk of type 2 diabetes in Danish individuals
}

\author{
Karina Banasik ${ }^{1 *}$, Mette Hollensted ${ }^{1}$, Ehm Andersson ${ }^{1}$, Thomas Spars $\varnothing^{1}$, Annelli Sandbæk², Torsten Lauritzen², \\ Torben Jørgensen ${ }^{3,4}$, Daniel R Witte ${ }^{5}$, Oluf Pedersen ${ }^{1,3,6,7}$ and Torben Hansen ${ }^{1,7,8}$
}

\begin{abstract}
Background: Variations within the FOXA family have been studied for a putative contribution to the risk of type 2 diabetes (T2D), and recently the minor T-allele of FOXA2 rs1209523 was reported to associate with decreased fasting plasma glucose levels in a study using a weighted false discovery rate control procedure to enhance the statistical power of genome wide association studies in detecting associations between low-frequency variants and a given trait. Thus, the primary aim of this study was to investigate whether the minor T-allele of rs1205923 in FOXA2 associated with 1) decreased fasting plasma glucose and 2) a lower risk of developing T2D. Secondly, we investigated whether rs1205923 in FOXA2 associated with other glucose-related phenotypes.

Methods: The variant was genotyped in Danish individuals from four different study populations using KASPar $^{\circledR}$ PCR SNP genotyping system. We examined for associations of the FOXA2 genotype with fasting plasma glucose and estimates of insulin release and insulin sensitivity following an oral glucose tolerance test in 6,162 Danish individuals from the population-based Inter99 study while association with T2D risk was assessed in 10,196 Danish individuals including four different study populations.
\end{abstract}

Results: The FOXA2 rs 1209523 was not associated with fasting plasma glucose (effect size $(\beta)=-0.03 \mathrm{mmol} / \mathrm{l}(95 \%$ $\mathrm{Cl}:-0.07 ; 0.01), p=0.2)$ in glucose-tolerant individuals from the general Danish population. Furthermore, when employing a case-control setting the variant showed no association with T2D (odds ratio $(\mathrm{OR})=0.82$ (95\%Cl: 0.621.07), $p=0.1$ ) among Danish individuals. However, when we performed the analysis in a subset of 6,022 non-obese individuals ( $\mathrm{BMI}<30 \mathrm{~kg} / \mathrm{m}^{2}$ ) an association with T2D was observed ( $\mathrm{OR}=0.68$ (95\%Cl: 0.49-0.94), $\left.p=0.02\right)$. Also, several indices of insulin release and $\beta$-cell function were associated with the minor T-allele of FOXA2 rs1209523 in non-obese individuals.

Conclusions: We failed to replicate association of the minor T-allele of FOXA2 rs1209523 with fasting plasma glucose in a population based sample of glucose tolerant individuals. More extensive studies are needed in order to fully elucidate the potential role of FOXA2 in glucose homeostasis.

\section{Background}

Type 2 diabetes (T2D) is a common and complex disease characterized by a state of hyperglycemia resulting from defects in insulin action combined with dysfunction of the pancreatic $\beta$-cell. Still, the underlying genetic factors affecting the susceptibility for developing T2D

\footnotetext{
* Correspondence: Karina.Banasik@sund.ku.dk

${ }^{1}$ The Novo Nordisk Foundation Center for Basic Metabolic Research, Section of Metabolic Genetics, Faculty of Health Sciences, University of Copenhagen, Copenhagen, Denmark

Full list of author information is available at the end of the article
}

and associated complications remain poorly elucidated. The Forkhead box A2 gene (FOXA2) encodes an upstream activator of the $\beta$-cell transcription factor network and variation in this gene is hypothesized to play a role in T2D pathogenesis. Studies have shown that mice lacking Foxa 2 in pancreatic $\beta$-cells are severely hypoglycaemic and show hypersecretion of insulin in response to both glucose and amino acid stimuli, suggesting that Foxa 2 has to be present in pancreatic $\beta$-cells in order to

\section{Biomed Central}

(c) 2012 Banasik et al; licensee BioMed Central Ltd. This is an Open Access article distributed under the terms of the Creative Commons Attribution License (http://creativecommons.org/licenses/by/2.0), which permits unrestricted use, distribution, and reproduction in any medium, provided the original work is properly cited. 
sustain appropriate circulating levels of insulin as well as for maintaining glucose homeostasis [1].

In humans, variations within the FOXA family have been studied for a putative contribution to the risk of developing T2D. A study by Zhu et al. found no statistically significant association between FOXA2 variants and T2D in a Japanese study sample $(n=208)$ [2]. In a study by Navas and colleagues, all three FOXA genes were sequenced in a sample of 96 T2D patients with mixed ancestry; however, no mutations within the coding regions of any of the three genes were found, suggesting that mutations within FOXA genes are not a common cause of T2D [3]. A more recent study, however, reported an association between the FOXA2 rs1055080 and a reduced risk of T2D in a North Indian study sample $(n=1,656)$ [4]. In line with this, Xing et al. identified FOXA2 rs1209523 (in high linkage disequilibrium (LD) with rs1055080 (CEU; $\left.\mathrm{r}^{2}=0.82\right)$ ) employing a weighted false discovery rate control procedure to enhance the statistical power of genome wide association studies (GWAS) in detecting associations between low-frequency variants and fasting plasma glucose levels [5]. This low-frequency variant (rs1209523; minor Tallele frequency $=4.3 \%$ ) was shown to be associated with lowered levels of fasting plasma glucose in both European Americans $\left(n=7,428, p=1.3 \times 10^{-3}\right)$ and African Americans $\left(n=2,029, p=6.7 \times 10^{-3}\right)$ [5]. A meta-analysis of the five included studies $(n=11,734)$ generated an estimated effect size of $-1.31 \mathrm{mg} / \mathrm{dl}$ fasting plasma glucose level per minor allele ( $p_{\text {all samples }}=2.2 \times$ $\left.10^{-11}\right)$ [5].

Therefore, the primary aim of the current study was to investigate whether the minor T-allele of rs 1205923 in FOXA2 associated with 1) decreased fasting plasma glucose among 6,162 Danish individuals from the population-based Inter99 study, and 2) a lower risk of developing T2D in 10,196 Danish individuals including four different study populations. Secondly, we investigated whether rs1205923 in FOXA2 associated with other traits related to glucose metabolism that could explain the previously found associations with T2D-related metabolic traits.

\section{Methods}

The study was conducted in accordance with the Helsinki Declaration and approved by the Ethical Committees of Copenhagen and Aarhus.

\section{Study participants}

Participants were of Danish nationality and prior to participation, a written informed consent was obtained from all individuals. Participants examined in the present study were from four different study populations: 1) The Inter99 study is a population-based randomized non-pharmacological intervention study for the prevention of ischaemic heart disease from the Research Centre for Prevention and Health in Glostrup, Denmark (ClinicalTrials.gov NTC00289237) [6]. A total of 6,162 participants with available genotypes for rs1209523 were classified as having normal glucose tolerance (NGT) ( $n$ $=4,567)$, impaired fasting glycemia $(n=508)$, impaired glucose tolerance $(n=707)$, screen-detected T2D $(n=$ $256)$, or previously diagnosed T2D $(n=124) ; 2)$ T2D patients recruited at Steno Diabetes Center (SDC) $(n=$ $1,695)$; 3) A random sample of middle-aged glucose-tolerant participants examined at SDC $(n=730)$ and 4$)$ T2D patients from the population-based, high-risk Addition Denmark screening and intervention study cohort $(n=1,609)$ (Anglo-Danish-Dutch Study of Intensive Treatment in People with Screen-Detected Diabetes in Primary Care) (ClinicalTrials.gov ID-no: NCT00237548). A standard $75 \mathrm{~g}$ oral glucose tolerance test (OGTT) was performed in participants from study group 1 and 3 . T2D was diagnosed according to World Health Organization 1999 criteria.

Analyses of quantitative diabetes-related traits were performed in glucose-tolerant individuals $(n=4,567)$, as well as in non-obese (BMI $\left.<30 \mathrm{~kg} / \mathrm{m}^{2}\right)$ individuals $(n=$ 4,022 ) from study population 1 . All T2D patients and glucose-tolerant individuals were included in the casecontrol study of T2D $(n=10,196)$. In the T2D case-control study of non-obese individuals, study participants with a BMI above 30 were excluded for both T2D individuals and glucose-tolerant controls.

\section{Genotyping}

The rs1209523 of FOXA2 was genotyped using KASPar ${ }^{\circledR}$ SNP Genotyping system (KBioscience, Hoddesdon, UK). The success rate was $97.3 \%$ with a $0.0 \%$ error rate estimated from re-genotyping of 972 replicate samples. The genotype distribution obeyed Hardy-Weinberg equilibrium in all study populations $(p>0.14)$.

\section{Biochemical and anthropometric measures}

Height and weight were measured in light indoor clothing and without shoes. Hip circumference was measured at its maximum, and waist circumference was measured in the upright position midway between the iliac crest and the lower costal margin [6] BMI was calculated as weight $(\mathrm{kg}) /$ height $^{2}\left(\mathrm{~m}^{2}\right)$. Blood samples were drawn after a $12 \mathrm{~h}$ overnight fast. A glucose oxidase method was used to analyze plasma glucose (Granutest; Merck, Darmstadt, Germany). Serum insulin (excluding des31,32 and intact proinsulin) was measured using the Autodelfia insulin kit (Perkin-Elmer/Wallac, Turku, Finland). Serum C-peptide concentrations were measured by a time-resolved fluoroimmunoassay (Auto-DELFIA C-peptide kit; Perkin-Elmer/Wallac, Turku, Finland). Homeostasis model assessment of insulin resistance 
(HOMA-IR) was calculated as: (fasting plasma glucose $(\mathrm{mmol} / \mathrm{l}) \times$ fasting serum insulin $(\mathrm{pmol} / \mathrm{l})) / 22.5$, and homeostasis model assessment of $\beta$-cell function (HOMA-B) was calculated as: $(20 \times$ fasting serum insulin $(\mathrm{pmol} / \mathrm{l})) /($ fasting plasma glucose $(\mathrm{mmol} / \mathrm{l})-3.5)$ [7]. Information on sex, BMI, plasma glucose levels, and serum insulin levels to time points 0,30 , and $120 \mathrm{~min}$ during an OGTT is used to calculate the BIGTT-acute insulin response (BIGTT-AIR) as well as the BIGTTinsulin sensitivity index (BIGTT-Si). These indices highly correlate with those obtained during an intravenous glucose tolerance test. The calculations were performed as previously described [8]. Insulinogenic index was calculated as: (serum insulin at $30 \mathrm{~min}(\mathrm{pmol} / \mathrm{l})$ fasting serum insulin $(\mathrm{pmol} / \mathrm{l})) /$ plasma glucose at 30 $\mathrm{min}(\mathrm{mmol} / \mathrm{l})$. Disposition index was calculated as insulinogenic index/HOMA-IR, and Matsuda whole body insulin sensitivity index ( $\mathrm{ISI}_{\text {Matsuda }}$ ) was calculated as $(10,000 / \sqrt{ }$ (fasting plasma glucose $\times$ fasting serum insulin) $\times$ (mean plasma glucose $\times$ mean serum insulin during OGTT)) [9]. The trapezoidal method was used to estimate the area under the curve (AUC) for plasma glucose, serum insulin and serum C-peptide, and the AUC for insulin/AUC for glucose ratio was calculated as AUC for insulin/AUC for glucose.

\section{Statistical analysis}

All statistical analyses were performed using R statistical software version 2.12.1 (available at http://www.rproject. org). A general linear model was applied to test quantitative traits in relation to genotype, using an additive genetic model and adjusting for age, sex, and BMI where appropriate. Prior to analyses, non-normally distributed data (measures of serum insulin, serum C-peptide levels, insulinogenic index, HOMA-IR, ISI $\mathrm{Catsuda}_{\text {, }}$ AUC for insulin/AUC for glucose ratio, and BIGTTAIR) were logarithmically transformed. Logistic regression was used to compare allele frequencies in the casecontrol analysis, and the analysis was adjusted for age, sex, and BMI. A p-value of less than 0.05 was considered statistically significant. The statistical power for detecting an effect on fasting plasma glucose of $0.07205 \mathrm{mmol} / \mathrm{l}$ per allele corresponding to $-1.31 \mathrm{mg} / \mathrm{dl}$ found by Xing and colleagues [5] was estimated using 1,000 simulations and a significance threshold of 0.05 . Based on the allele frequency of the variant and the sample size of 4,368 non-diabetic successfully genotyped individuals, we estimated a statistical power of $93 \%$ to detect an association. For comparison, the statistical power to detect an effect on fasting plasma glucose of $0.06,0.05,0.04$, or $0.03 \mathrm{mmol} / \mathrm{l}$ per allele were $79 \%$, $66 \%, 46 \%$, or $30 \%$, respectively.

The statistical power calculation for the case-control analysis was done using CaTS, power calculations for large genetic association studies http://www.sph.umich. $\mathrm{edu} / \mathrm{csg} / \mathrm{abecasis} / \mathrm{cats} /$, and the statistical power to detect an OR of $0.85,0.90$, or 0.95 for rs1209523 of FOXA2 was estimated to be $50 \%, 26 \%$, or $10 \%$, respectively (significance level: $p<0.05$, minor allele frequency $(\mathrm{MAF})=4 \%$, estimated $\mathrm{T} 2 \mathrm{D}$ prevalence in the background population $=0.08$ ).

\section{Functional prediction}

FASTSNP (Function Analysis and Selection Tool for Single Nucleotide Polymorphisms; http://fastsnp.ibms. sinica.edu.tw) was used to predict the function of rs1209523 in FOXA2.

\section{External data}

Data on glycemic traits have been contributed by MAGIC investigators and have been downloaded from http://www.magicinvestigators.org[10]. Data on T2D were available through the DIAGRAM meta-analysis [11].

\section{Results and discussion}

\section{Association with fasting plasma glucose}

We analyzed the FOXA2 rs1209523 minor T-allele which is located in the promoter region of the gene and is predicted by FASTSNP to have a very low to medium functional effect on FOXA2 function, for association with fasting plasma glucose in glucose-tolerant individuals from the Inter99 study population. No statistically significant association was found (effect size $(\beta)=-0.03$ $\mathrm{mmol} / \mathrm{l}$ (95\%CI: -0.07; 0.01), $p=0.2$ ) (Table 1). Considering the high statistical power to detect an association in the present study, this suggests that the variant may only have a minor effect on fasting plasma glucose levels among Danish individuals. Similarly, no associations were found between rs1209523 and plasma glucose levels after 30-min and 120-min during an OGTT (Table 1).

The weighted false discovery rate control procedure applied by Xing and colleagues to enhance the statistical power of detecting associations with low frequency variants was shown to boost the $p$-values of variants with even small effect sizes to genome-wide significance [5]. As mentioned by the authors, the weighted false discovery rate control procedure is a prototype and its properties in GWAS should be further investigated. A large meta-analysis $(n=46,263)$ of European-ancestry-based GWAS on fasting glucose levels failed to identify a genome-wide significant association with FOXA2 ( $\beta=$ $-0.028 \mathrm{mmol} / \mathrm{l}, p=0.00394)$ [10]. This may, as Xing et al. suggest, be attributed to the low MAF of the variant which makes it less likely to detect an association compared to more frequent variants with a similar effect size. However, it is more likely that the effect size 
Table 1 Anthropometric and metabolic characteristics of successfully genotyped glucose-tolerant Danish individuals from the Inter99 study according to rs1209523 FOXA2 genotype

\begin{tabular}{|c|c|c|c|c|c|}
\hline rs1209523 & $\mathrm{CC}$ & CT & $\pi$ & $\beta[95 \% \mathrm{Cl}]$ & $p_{\text {add }}$ \\
\hline$n$ (men/women) & $4,091(1,880 / 2,211)$ & $269(133 / 136)$ & $8(6 / 2)$ & & \\
\hline Age (years) ${ }^{¥}$ & $45.2 \pm 7.9$ & $44.8 \pm 7.3$ & $45.7 \pm 7.2$ & & \\
\hline $\mathrm{BMI}^{*}$ & $25.5 \pm 4.1$ & $25.5 \pm 3.6$ & $25.8 \pm 2.4$ & $-0.02[-0.49 ; 0.45]$ & 0.9 \\
\hline \multicolumn{6}{|l|}{ Plasma glucose $(\mathrm{mmol} / \mathrm{l})$} \\
\hline Fasting $^{¥}$ & $5.3 \pm 0.4$ & $5.3 \pm 0.4$ & $5.6 \pm 0.3$ & $-0.03[-0.07 ; 0.01]$ & 0.2 \\
\hline 30-min during an OGTT & $8.2 \pm 1.5$ & $8.2 \pm 1.5$ & $8.9 \pm 1.1$ & $0.04[-0.12 ; 0.21]$ & 0.6 \\
\hline 120-min during an OGTT & $5.5 \pm 1.1$ & $5.5 \pm 1.1$ & $5.3 \pm 1.2$ & $-0.02[-0.14 ; 0.11]$ & 0.8 \\
\hline Incremental AUC & $181 \pm 101$ & $186 \pm 98$ & $185 \pm 73$ & $\begin{array}{c}5.36[-6.26 ; \\
16.98]\end{array}$ & 0.4 \\
\hline \multicolumn{6}{|l|}{ Serum insulin (pmol/l) } \\
\hline Fasting & $31(22-45)$ & $34(23-49)$ & $42(30-50)$ & $5.0 \%[-0.9 ; 10.8]$ & 0.1 \\
\hline 30-min during an OGTT & $242(175-344)$ & $248(188-346)$ & $314(232-425)$ & $7.9 \%[2.1 ; 13.7]$ & 0.008 \\
\hline 120-min during an OGTT & $136(86-209)$ & $137(94-216)$ & $212(120-240)$ & $9.3 \%[1.4 ; 17.3]$ & 0.02 \\
\hline Incremental AUC & $17,720(12,540-25,020)$ & $17,300(13,680-25,800)$ & $18,360(14,250-28,120)$ & $7.9 \%[1.6 ; 14.2]$ & 0.01 \\
\hline \multicolumn{6}{|l|}{ Serum C-peptide (pmol/l) } \\
\hline Fasting & $493(391-631)$ & $520(407-663)$ & $602(564-726)$ & $3.8 \%[0.2 ; 7.5]$ & 0.04 \\
\hline 30-min during an OGTT & $1,870(1,470-2,360)$ & $1,950(1,580-2,412)$ & $2,505(1,685-2,738)$ & $4.3 \%[0.4 ; 8.2]$ & 0.03 \\
\hline 120-min during an OGTT & $1,960(1,480-2,490)$ & $1,990(1,580-2,520)$ & $2,485(1,975-2,968)$ & $5.0 \%[0.6 ; 9.3]$ & 0.03 \\
\hline Incremental AUC & $\begin{array}{c}147,800(117,200- \\
183,200)\end{array}$ & $\begin{array}{c}150,700(122,700- \\
185,400)\end{array}$ & $\begin{array}{c}176,500(150,000- \\
199,400)\end{array}$ & $4.6 \%[0.7 ; 8.4]$ & 0.02 \\
\hline
\end{tabular}

\section{Derived indices}

$\beta$-cell function

\begin{tabular}{|c|c|c|c|c|c|}
\hline Insulinogenic index & $25.8(17.9-37.6)$ & $26.0(19.6-39.0)$ & $34.3(19.7-42.4)$ & $7.0 \%[0.5 ; 13.5]$ & 0.03 \\
\hline BIGTT-AIR & $1,672(1,348-2,099)$ & $1,710(1,387-2,191)$ & $1,455(1,238-2,500)$ & $3.5 \%[-1.1 ; 8.1]$ & 0.1 \\
\hline HOMA-B & $353(248-508)$ & $380(267-560)$ & $401(310-488)$ & $6.9 \%[0.9 ; 12.9]$ & 0.02 \\
\hline AUCinsulin/AUCglucose & $27.3(20.2-37.4)$ & $27.8(21.1-39.7)$ & $29.2(23.2-40.8)$ & $6.5 \%[1.2 ; 11.9]$ & 0.02 \\
\hline \multicolumn{6}{|l|}{ Insulin sensitivity } \\
\hline HOMA-IR & $7.4(5.2-10.9)$ & $7.9(5.4-11.8)$ & $10.5(7.8-11.8)$ & $4.4 \%[-1.6 ; 10.4]$ & 0.2 \\
\hline$\overline{\mathrm{BIGTT}_{\mathrm{i}}^{*}}$ & $10.4 \pm 3.7$ & $10.1 \pm 3.7$ & $8.6 \pm 3.3$ & $-0.33[-0.78 ; 0.12]$ & 0.2 \\
\hline$\overline{I S I_{\text {Matsuda }}}$ & $25.9(18.2-35.6)$ & $24.4(16.8-34.5)$ & $19.2(15.0-26.5)$ & $-5.8 \%[-11.2 ;-0.4]$ & 0.03 \\
\hline
\end{tabular}

$\beta$-cell function corrected for insulin sensitivity

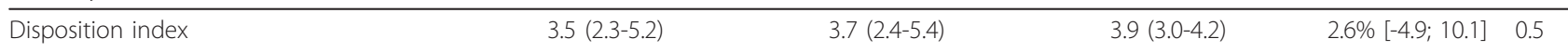

Data are unadjusted means $\pm \mathrm{SD}^{*}$ or medians (interquartile range). Values of serum insulin, serum c-peptide, and insulin-derived indices were logarithmically transformed prior to statistical analyses, and their effect sizes are presented as the increase/decrease in percent. Effect sizes ( $\beta$ ) and $p$-values shown are for an additive genetic model and are adjusted for age, sex, and BMI where appropriate. $\mathrm{Cl}$, confidence interval; add, additive; AUC, area under the curve.

observed by Xing and colleagues is overestimated as an example of "winners curse", and a lower effect size for fasting plasma glucose would cause a considerably decreased power to detect associations in this study. Larger studies in study populations of different origin are needed to evaluate an effect of FOXA2 rs1209523 on fasting plasma glucose levels.

\section{Association with T2D}

We investigated, in a case-control setting $\left(n_{\text {cases }}(\mathrm{CC} / \mathrm{CT} /\right.$ TT): $3340 / 166 / 1$ vs. $\left.n_{\text {controls }}(C C / C T / T T): 4567 / 300 / 8\right)$, whether rs1209523 of FOXA2 associated with a decreased risk of developing T2D as indicated by the findings by Xing et al. [5]. No statistically significant association with T2D was found (odds ratio $(\mathrm{OR})=0.82$ (95\%CI: 0.62-1.07), $p=0.1$ ) (Table 2). The OR, however, indicates that the minor T-allele of rs1209523 may exert a protective effect on T2D risk, although not statistically significant. Yet, the observed effect on T2D is not comparable to the one observed in the DIAGRAM metaanalysis (OR $=1.12(0.94-1.34), p=0.2)$ [11]. Considering the relatively low statistical power in our study, the indication of a protective effect of the variant on T2D is to be considered a chance-finding. 
Table 2 Genotype distribution and allele frequency for FOXA2 rs1209523 among patients with T2D and glucosetolerant control individuals

\begin{tabular}{|c|c|c|c|c|c|c|c|}
\hline & $n$ (men/women) & CC (\%) & CT (\%) & Tा (\%) & $\begin{array}{l}\text { MAF } \\
(95 \% \mathrm{Cl})\end{array}$ & OR $(95 \% \mathrm{Cl})$ & $P_{\text {add }}$ \\
\hline \multicolumn{8}{|c|}{ All individuals } \\
\hline$\overline{\mathrm{NGT}}$ & $4,875(2,256 / 2,619)$ & $4,567(93.7)$ & $300(6.2)$ & $8(0.2)$ & $\begin{array}{l}3.2 \\
(2.9-3.6)\end{array}$ & $0.82(0.62-1.07)$ & 0.1 \\
\hline $\mathrm{T} 2 \mathrm{D}$ & $3,507(2,084 / 1,423)$ & $3,340(95.2)$ & $166(4.7)$ & $1(0.1)$ & $\begin{array}{l}2.4 \\
(2.1-2.8)\end{array}$ & & \\
\hline \multicolumn{8}{|c|}{ Non-obese individuals $\left(B M I<30 \mathrm{~kg} / \mathrm{m}^{2}\right)$} \\
\hline$\overline{N G T}$ & $4,292(1,999 / 2,293)$ & $4,012(93.5)$ & $272(6.3)$ & $8(0.2)$ & $\begin{array}{l}3.4 \\
(3.0-3.8)\end{array}$ & $0.68(0.49-0.94)$ & 0.02 \\
\hline $\mathrm{T} 2 \mathrm{D}$ & $1,730(1,096 / 634)$ & $1,653(95.5)$ & $77(4.5)$ & $0(0)$ & $\begin{array}{l}2.2 \\
(1.8-2.8)\end{array}$ & & \\
\hline
\end{tabular}

Number of individuals divided into genotype groups (\% in each group), and frequencies of the minor allele (MAF) in percentages. Logistic regression was used to compare allele frequencies $\left(P_{\text {add }}\right)$. The odds ratios $(\mathrm{OR})$ and the $95 \%$ confidence interval $(\mathrm{Cl})$ are given for comparison of allele frequency. NGT: Glucose-tolerant individuals, T2D: type 2 diabetic patients.

On the contrary, our finding corresponded well to the findings by Tabassum and colleagues where a protective effect on T2D risk among normal-weight North Indians $(n=566)$ was observed for FOXA2 rs1055080 (OR = 0.59 (0.40-0.88), $p=0.011$ ) [4]. Due to the strong LD between $\mathrm{rs} 1055080$ and $\mathrm{rs} 1209523\left(\mathrm{CEU} ; \mathrm{r}^{2}=0.82\right)$ the association signals are likely to originate from the same causal variant. Therefore, we investigated whether rs1209523 of FOXA2 associated with a decreased risk of developing T2D among non-obese $\left(\mathrm{BMI}<30 \mathrm{~kg} / \mathrm{m}^{2}\right)$ Danish individuals $\left(n_{\text {cases }(B M I}<30\right)(C C / C T / T T): 1653 / 77 /$ 0 vs. $\left.n_{\text {controls }(\mathrm{BMI}<30)}(\mathrm{CC} / \mathrm{CT} / \mathrm{TT}): 4012 / 272 / 8\right)$ (Table 2). Here we found that rs1209523 of FOXA2 associated with a statistically significant decrease in the risk of developing T2D (OR $=0.68$ (95\%CI: 0.49-0.94), $p=$ 0.02) (Table 2). Whether this is a true finding needs further investigation in other independent study populations.

\section{Associations with glucose-related phenotypes}

When FOXA2 rs1209523 was analyzed for associations with glucose-related phenotypes, the T-allele significantly associated with increased serum insulin levels after 30 - $\min (\beta=7.9 \%(2.1 ; 13.7), p=0.008)$ and 120 $\min (\beta=9.3 \%(1.4 ; 17.3), p=0.02)$ during an OGTT (Table 1). Furthermore, the rs1209523 T-allele associated with an increased incremental AUC for insulin $(\beta$ $=7.9 \%(1.6 ; 14.2), p=0.01)$ during the OGTT (Table 1$)$. The associations were underpinned by significant associations for serum C-peptide levels during the OGTT (Table 1). In line with these results, several indices of insulin release and $\beta$-cell function showed significantly increased levels for the FOXA2 rs1209523 minor T-allele (Table 1). The indication of a general effect on $\beta$-cell function is supported by the findings reported by the MAGIC investigators where the T-allele of rs1209523 in FOXA2 significantly associated with an increased
HOMA-B ( $\beta=0.037$ (standard error: 0.0093), $p=6.595$ $\times 10^{-5}$ ).

To test whether these associations were independent of BMI, we conducted the analysis without adjusting for $\mathrm{BMI}$, and the associations remained significant (data not shown). Likewise, stratifying the analysis according to BMI using a cut-off of $30 \mathrm{~kg} / \mathrm{m}^{2}$ showed that the significant associations were driven by the non-obese (BMI < $30 \mathrm{~kg} / \mathrm{m}^{2}$ ) individuals (Table 3). However, these data should be interpreted with caution since no obese individuals were homozygous for the minor $\mathrm{T}$-allele of rs1209523. Indices of insulin sensitivity (HOMA-IR and BIGTT-S ${ }_{\mathrm{i}}$ ) showed no evidence of associations with FOXA2 rs1209523 among glucose-tolerant individuals.

None of the identified associations in this study would remain significant after Bonferroni corrections.

Altogether, our findings may suggest that the improved $\beta$-cell function in carriers of the rs1209523 minor $\mathrm{T}$-allele may play a role in the observed lowered fasting plasma glucose levels. A study by Gao et al. showed that inducible ablation of both Foxa1 and Foxa2 in mature mouse $\beta$-cells lead to impaired glucose homeostasis with impaired insulin secretion, suggesting that these transcription factors play a crucial role in the development and maintenance of $\beta$-cell specific secretory and metabolic pathways [12]. Interestingly, Gao et al. also showed that the gene encoding hydroxyacylcoenzyme A dehydrogenase ( $\mathrm{Hadh}$ ) is down regulated 2.4 -fold in Foxa 2 deficient $\beta$-cells and 5.4-fold in $\beta$-cells lacking both Foxa1 and Foxa2 [12]. Decreased expression of the gene encoding a related mitochondrial fatty acid oxidation enzyme, the short-chain specific acylCoA dehydrogenase (ACADS) has been hypothesized to impair insulin secretion [13], and a study by our group has previously shown that the minor C-allele of rs2014355 in ACADS associated with reduced measures of glucose-stimulated insulin release [14]. Thus, altered 
Table 3 Anthropometric and metabolic characteristics of successfully genotyped non-obese $\left(\mathrm{BMI}<30 \mathrm{~kg} / \mathrm{m}^{2}\right) \mathrm{glucose}-$ tolerant Danish individuals from the Inter99 study according to rs1209523 FOXA2 genotype

\begin{tabular}{|c|c|c|c|c|c|}
\hline rs1209523 & $\mathrm{CC}$ & CT & $\pi T$ & $\beta[95 \% \mathrm{Cl}]$ & $p_{\text {add }}$ \\
\hline$n$ (men/women) & $3,597(1,663 / 1,934)$ & $244(121 / 123)$ & $8(6 / 2)$ & & \\
\hline Age $\left(\right.$ years) ${ }^{*}$ & $45.1 \pm 7.9$ & $44.7 \pm 7.2$ & $45.7 \pm 7.2$ & & \\
\hline$\overline{\mathrm{BMI}^{*}}$ & $24.1 \pm 7.9$ & $24.7 \pm 2.8$ & $25.8 \pm 2.4$ & $0.32[-0.004 ; 0.65]$ & 0.05 \\
\hline \multicolumn{6}{|l|}{ Plasma glucose $(\mathrm{mmol} / \mathrm{l})$} \\
\hline Fasting $^{*}$ & $5.3 \pm 0.4$ & $5.2 \pm 0.4$ & $5.6 \pm 0.3$ & $-0.03[-0.07 ; 0.02]$ & 0.3 \\
\hline 30-min during an OGTT & $8.1 \pm 1.5$ & $8.2 \pm 1.4$ & $8.9 \pm 1.1$ & $0.05[-0.13 ; 0.22]$ & 0.6 \\
\hline 120-min during an OGT ${ }^{*}$ & $5.4 \pm 1.1$ & $5.4 \pm 1.1$ & $5.3 \pm 1.2$ & $-0.01[-0.15 ; 0.12]$ & 0.8 \\
\hline Incremental $A \cup C^{¥}$ & $176 \pm 102$ & $182 \pm 96$ & $185 \pm 73$ & $5.64[-6.64 ; 17.92]$ & 0.4 \\
\hline \multicolumn{6}{|l|}{ Serum insulin (pmol/l) } \\
\hline Fasting & $29(21-41)$ & $32(22-44)$ & $42(30-50)$ & $6.5 \%[0.02 ; 13.0]$ & 0.2 \\
\hline 30-min during an OGTT & $229(168-321)$ & $244(186-327)$ & $314(232-425)$ & $9.2 \%[2.9 ; 15.6]$ & 0.01 \\
\hline 120-min during an OGTT & $131(83-194)$ & $135(92-198)$ & $212(120-240)$ & $10.9 \%[2.5 ; 19.4]$ & 0.03 \\
\hline Incremental AUC & $16,880(12,140-23,300)$ & $16,500(13,240-23,430)$ & $18,360(14,250-28,120)$ & $9.1 \%[2.4 ; 15.9]$ & 0.02 \\
\hline \multicolumn{6}{|l|}{ Serum C-peptide (pmol/l) } \\
\hline Fasting & $473(381-592)$ & $495(398-604)$ & $602(564-726)$ & $4.7 \%[0.6 ; 8.8]$ & 0.09 \\
\hline 30-min during an OGTT & $1,820(1,440-2,280)$ & $1,920(1,525-2,315)$ & $2,505(1,685-2,738)$ & $5.2 \%[1.0 ; 9.4]$ & 0.05 \\
\hline 120-min during an OGTT & $1,900(1,450-2,400)$ & $1,950(1,548-2,420)$ & $2,485(1,975-2,968)$ & $5.8 \%[1.2 ; 10.4]$ & 0.03 \\
\hline Incremental AUC & $\begin{array}{c}144,200(115,100- \\
177,800)\end{array}$ & $\begin{array}{c}149,000(122,000- \\
182,000)\end{array}$ & $\begin{array}{c}176,500(150,000- \\
199,400)\end{array}$ & $5.4 \%[1.3 ; 9.5]$ & 0.03 \\
\hline \multicolumn{6}{|l|}{ Derived indices } \\
\hline \multicolumn{6}{|l|}{$\beta$-cell function } \\
\hline Insulinogenic index & $24.7(17.3-35.7)$ & $24.9(18.5-36.9)$ & $34.3(19.7-42.4)$ & $8.2 \%[1.2 ; 15.1]$ & 0.04 \\
\hline BIGTT-AIR & $1,596(1,311-1,973)$ & $1,665(1,361-2,060)$ & $1,455(1,238-2,500)$ & $5.7 \%[1.4 ; 10.0]$ & 0.01 \\
\hline HOMA-B & 337 (240-399) & 367 (263-515) & 401 (310-488) & $6.7 \%[0.4 ; 13.1]$ & 0.04 \\
\hline AUCinsulin/AUCglucose & $26.0(19.6-34.9)$ & $27.0(20.4-37.9)$ & $29.2(23.2-40.8)$ & $7.7 \%[2.0 ; 13.5]$ & 0.01 \\
\hline \multicolumn{6}{|l|}{ Insulin sensitivity } \\
\hline HOMA-IR & $7.0(4.9-9.8)$ & $7.5(5.0-10.6)$ & $10.5(7.8-11.8)$ & $5.9 \%[-0.8 ; 12.7]$ & 0.2 \\
\hline$\overline{B I G T T-S_{i}^{*}}$ & $11.0 \pm 3.3$ & $10.6 \pm 3.5$ & $8.6 \pm 3.3$ & $-0.53[-0.95 ; 0.10]$ & 0.02 \\
\hline$|S|_{\text {Matsuda }}$ & $27.4(19.9-36.9)$ & $26.6(18.1-35.7)$ & $19.2(15.0-26.5)$ & $-7.2 \%[-13.5 ;-1.1]$ & 0.02 \\
\hline \multicolumn{6}{|c|}{$\beta$-cell function corrected for insulin sensitivity } \\
\hline Disposition index & $3.6(2.4-5.3)$ & $3.9(2.4-5.6)$ & $3.9(3.0-4.2)$ & $2.5 \%[-5.4 ; 10.5]$ & 0.5 \\
\hline
\end{tabular}

Data are unadjusted means $\pm \mathrm{SD}^{¥}$ or medians (interquartile range). Values of serum insulin, serum c-peptide, and insulin-derived indices were logarithmically transformed prior to statistical analyses, and their effect sizes are presented as the increase/decrease in percent. Effect sizes ( $\beta$ ) and $p$-values shown are for an additive genetic model and are adjusted for age and sex. $\mathrm{Cl}$, confidence interval; add, additive; AUC, area under the curve.

FOXA2 expression may influence insulin secretion, potentially in combination with the regulation of genes expressed in the same molecular pathway.

\section{Conclusions}

The FOXA2 rs1209523 was not significantly associated with fasting plasma glucose in glucose-tolerant individuals from the general Danish population of middleaged people. Furthermore, when employing a case-control setting the $\mathrm{T}$-allele was not found to be significantly associated with the risk of developing T2D. However, when we performed the analysis exclusively in nonobese individuals $\left(\mathrm{BMI}<30 \mathrm{~kg} / \mathrm{m}^{2}\right)$, a significant association with T2D was observed. Also, several indices of insulin release and $\beta$-cell function showed significantly increased levels for the FOXA2 rs1209523 minor $\mathrm{T}$-allele in the non-obese study population. More extensive studies are needed in order to fully elucidate the potential contribution of variation in FOXA2 to glucose homeostasis.

List of abbreviations

AUC: Area under the curve; BIGTT-AIR: BIGTT-acute insulin response; BIGTT-Si: BIGTT-insulin sensitivity index; FOXA: Forkhead box A; GWAS: Genome-wide association study; HOMA-B: Homeostasis model assessment of $\beta$-cell function; HOMA-IR: Homeostasis model assessment of insulin resistance; IR: Insulin resistance; ISI Matsuda: Matsuda whole body insulin sensitivity index; LD: 
Linkage disequilibrium; OGTT: Oral glucose tolerance test; SDC: Steno Diabetes Center; SNP: Single nucleotide polymorphism; T2D: Type 2 diabetes.

\section{Acknowledgements}

The authors wish to thank A. Forman, T. Lorentzen and M. Stendal for technical assistance, G. Lademann for secretarial support, A. Nielsen and P. Sandbeck for data management and M. Kristensen for grant management. This work received support from the Lundbeck Foundation Centre for Applied Medical Genomics in Personalized Disease Prediction, Prevention and Care (LuCAMP, http://www.lucamp.org). The Inter99 was initiated by Torben Jørgensen (PI), Knut Borch-Johnsen (co-PI), Hans Ibsen and Troels F. Thomsen. The steering committee comprises the former two and Charlotta Pisinger.

\section{Author details}

${ }^{1}$ The Novo Nordisk Foundation Center for Basic Metabolic Research, Section of Metabolic Genetics, Faculty of Health Sciences, University of Copenhagen, Copenhagen, Denmark. ${ }^{2}$ Department of General Practice, University of Aarhus, Aarhus, Denmark. ${ }^{3}$ Faculty of Health Sciences, University of Copenhagen, Copenhagen, Denmark. ${ }^{4}$ Research Centre for Prevention and Health, Glostrup University Hospital, Glostrup, Denmark. ${ }^{5}$ Steno Diabetes Center, Gentofte, Denmark. ${ }^{6}$ Faculty of Health Sciences, University of Aarhus, Aarhus, Denmark. ${ }^{7}$ Hagedorn Research Institute, Gentofte, Denmark. ${ }^{8}$ Faculty of Health Sciences, University of Southern Denmark, Odense, Denmark.

\section{Authors' contributions}

The concept and idea regarding the epidemiological studies underlying the study populations was conceived by $\mathrm{TJ}, \mathrm{AS}, \mathrm{TL}, \mathrm{OP}$, and $\mathrm{TH}$. The collection of study subjects was planned and performed by $T J, A S, T L, O P$, and $T H$. The original hypothesis regarding the study was conceived by TH and approved by OP. Detailed planning of analyses and study design was performed by $\mathrm{KB}, \mathrm{MH}$ and $\mathrm{TS}$ and approved by $\mathrm{OP}$ and $\mathrm{TH}$. $\mathrm{KB}, \mathrm{MH}, \mathrm{EA}, \mathrm{DW}, \mathrm{OP}$, and $\mathrm{TH}$ contributed to the establishment of study population databases specific for this study. Statistical analyses in association studies were performed by KB, $\mathrm{MH}$, TS and EA. The first manuscript was written by $\mathrm{KB}$ and $\mathrm{MH}$ with equal contribution and the final draft was finalized by $\mathrm{KB}, \mathrm{MH}, \mathrm{OP}$ and $\mathrm{TH}$. All authors revised the manuscript and contributed to the discussion. The final manuscript was read and approved by all authors.

\section{Competing interests}

K. Banasik, T. Hansen and O. Pedersen hold employee shares in Novo Nordisk A/S. All other authors declare that there is no competing interest associated with this manuscript.

Received: 28 July 2011 Accepted: 12 February 2012

Published: 12 February 2012

\section{References}

1. Sund NJ, Vatamaniuk MZ, Casey M, Ang SL, Magnuson MA, Stoffers DA, Matschinsky FM, Kaestner KH: Tissue-specific deletion of Foxa2 in pancreatic beta cells results in hyperinsulinemic hypoglycemia. Genes Dev 2001, 15(13):1706-1715.

2. Zhu Q, Yamagata K, Yu L, Tomura H, Yamada S, Yang Q, Yoshiuchi I, Sumi S, Miyagawa J, Takeda J, Hanafusa T, Matsuzawa Y: Identification of missense mutations in the hepatocyte nuclear factor-3beta gene in Japanese subjects with late-onset Type II diabetes mellitus. Diabetologia 2000, 43(9):1197-1200.

3. Navas MA, Vaisse C, Boger S, Heimesaat M, Kollee LA, Stoffel M: The human HNF-3 genes: cloning, partial sequence and mutation screening in patients with impaired glucose homeostasis. Hum Hered 2000, 50(6):370-381.

4. Tabassum R, Chavali S, Dwivedi OP, Tandon N, Bharadwaj D: Genetic variants of FOXA2: risk of type 2 diabetes and effect on metabolic traits in North Indians. Journal of Human Genetics 2008, 53(11-12):957-965.

5. Xing $C$, Cohen $J C$, Boerwinkle E: A weighted false discovery rate control procedure reveals alleles at FOXA2 that influence fasting glucose levels. Am J Hum Genet 2010, 86(3):440-446.

6. Jørgensen T, Borch-Johnsen K, Thomsen TF, Ibsen H, Glumer C, Pisinger C: $A$ randomized non-pharmacological intervention study for prevention of ischaemic heart disease: baseline results Inter99. Eur I Cardiovasc Prev Rehabil 2003, 10(5):377-386.

7. Matthews DR, Hosker JP, Rudenski AS, Naylor BA, Treacher DF, Turner RC: Homeostasis model assessment: insulin resistance and beta-cell function from fasting plasma glucose and insulin concentrations in man. Diabetologia 1985, 28(7):412-419.

8. Hansen T, Drivsholm T, Urhammer SA, Palacios RT, Volund A, BorchJohnsen K, Pedersen O: The BIGTT test: a novel test for simultaneous measurement of pancreatic beta-cell function, insulin sensitivity, and glucose tolerance. Diabetes Care 2007, 30(2):257-262.

9. Matsuda M, DeFronzo RA: Insulin sensitivity indices obtained from oral glucose tolerance testing: comparison with the euglycemic insulin clamp. Diabetes Care 1999, 22(9):1462-1470.

10. Dupuis J, Langenberg C, Prokopenko I, Saxena R, Soranzo N, Jackson AU, Wheeler E, Glazer NL, Bouatia-Naji N, Gloyn AL, Lindgren CM, Magi R, Morris AP, Randall J, Johnson T, Elliott P, Rybin D, Thorleifsson G, Steinthorsdottir V, Henneman P, Grallert H, Dehghan A, Hottenga JJ, Franklin CS, Navarro P, Song K, Goel A, Perry JR, Egan JM, Lajunen T, et al: New genetic loci implicated in fasting glucose homeostasis and their impact on type 2 diabetes risk. Nat Genet 2010, 42(2):105-116.

11. Zeggini E, Scott $L$, Saxena R, Voight BF, Marchini JL, Hu T, de Bakker PI, Abecasis GR, Almgren P, Andersen G, Ardlie K, Bostrom KB, Bergman RN, Bonnycastle LL, Borch-Johnsen K, Burtt NP, Chen H, Chines PS, Daly MJ, Deodhar P, Ding CJ, Doney AS, Duren WL, Elliott KS, Erdos MR, Frayling TM, Freathy RM, Gianniny L, Grallert H, Grarup N, et al: Meta-analysis of genome-wide association data and large-scale replication identifies additional susceptibility loci for type 2 diabetes. Nat Genet 2008, 40(5):638-645.

12. Gao N, Le Lay J, Qin W, Doliba N, Schug J, Fox AJ, Smirnova O, Matschinsky FM, Kaestner KH: Foxa1 and Foxa2 maintain the metabolic and secretory features of the mature beta-cell. Mol Endocrinol 2010, 24(8):1594-1604

13. Clayton PT, Eaton $S$, ynsley-Green A, Edginton M, Hussain K, Krywawych $S$, Datta V, Malingre HE, Berger R, van dBl: Hyperinsulinism in short-chain L3-hydroxyacyl-CoA dehydrogenase deficiency reveals the importance of beta-oxidation in insulin secretion. JClin/nvest 2001, 108(3):457-465.

14. Hornbak M, Banasik K, Justesen JM, Krarup NT, Sandholt CH, Andersson $A$, Sandbaek A, Lauritzen T, Pisinger C, Witte DR, Sorensen TA, Pedersen O, Hansen T: The minor C-allele of rs2014355 in ACADS is associated with reduced insulin release following an oral glucose load. BMC Med Genet 2011, 12:4.

\section{Pre-publication history}

The pre-publication history for this paper can be accessed here: http://www.biomedcentral.com/1471-2350/13/10/prepub

\section{doi:10.1186/1471-2350-13-10}

Cite this article as: Banasik et al:: The effect of FOXA2 rs1209523 on glucose-related phenotypes and risk of type 2 diabetes in Danish individuals. BMC Medical Genetics 2012 13:10.

\section{Submit your next manuscript to BioMed Central and take full advantage of:}

- Convenient online submission

- Thorough peer review

- No space constraints or color figure charges

- Immediate publication on acceptance

- Inclusion in PubMed, CAS, Scopus and Google Scholar

- Research which is freely available for redistribution

Submit your manuscript at www.biomedcentral.com/submit
C Biomed Central 